even if it is true on site, the nature of the dusts involved and the quantities affecting the local population could well be different

Afacan's allusion to research into occupational exposures in the mining industry is irrelevant in the community setting and his reliance on occupational exposure standards is unwise. The numbers of people employed in open cast mining is low, so it is unlikely to improve community health by bringing jobs and increased prosperity to the area. Chambers has eloquently expressed the feelings that the "spectre of open cast mining" brings to a community.'

We would welcome a major epidemiological study to evaluate the size of the risk and the nature of the mechanisms involved, but in 1989 the Secretary of State for Wales felt that no such study was required.

J M F TEMPLE

Glynneath,

West Glamorgan SA11 5AL

A M SYKES

University College,

Swansea

1 Chambers J. Paradise postponed. BMF 1988;297:1688-90.

\section{Exercise, fitness, and health}

EDITOR,-Daphne Gloag's editorial confirms what all exercise enthusiasts have been saying for years: that exercise is good for us and that most people do not take enough.' Gloag concludes that all doctors should ask about exercise when they see patients and advise on suitable exercise and local facilities. Doctors may also, however, unwittingly reduce some patients' capacity to take exercise by prescribing drugs that may interfere with exercise metabolism. Endurance exercise has specific benefits by favourably modifying lipid profiles. Any endurance exercise of moderate intensity (about 50\% maximal oxygen uptake) relies heavily on oxidation of fat for resynthesis of ATP and production of energy, thereby preserving carbohydrate stores. Drugs that modify the metabolism of fat and reduce the availability of fatty acids for oxidation would therefore be expected to have an impact on a patient's capacity to take exercise. Our recently completed trial suggests that a lipid lowering drug (a derivative of nicotinic acid) considerably reduced oxidation of fat, a fibrate had an intermediate effect, and a 3-hydroxy-3methylglutaryl coenzyme A reductase inhibitor had no effect.

A suitably designed exercise regimen is often prescribed as part of a rehabilitation programme for patients suffering from hypertension or angina or recovering from myocardial infarction. Concurrent drug treatment for such patients may include a $\beta$ blocker, which has a cardioprotective effect. ${ }^{3}$ Our observations suggest that in comparable doses $\beta_{1}$ selective agents may have less of an impact on total oxidation of fat than nonselective agents. During one hour's exercise the mean proportion of energy supplied by fat in eight healthy men was $41 \cdot 5 \%$ (SD $10 \cdot 9 \%$ ) with a placebo $34 \cdot 2 \%(10 \%)$ with a $\beta_{1}$ selective drug, and $28 \cdot 6 \%$ $(8 \cdot 2 \%)$ with a non-selective drug. Furthermore, $\beta_{1}$ selective drugs reduce the unwanted $\beta_{2}$ mediated effects on glucose metabolism and peripheral vasoconstriction associated with non-selective drugs and should therefore have less of an impact on exercise metabolism. Doctors might also give advice on the timing of exercise as with most $\beta$ blockers peak plasma concentrations are reached one to three hours after an oral dose, with exercise being more difficult during this period.

Thus care should be taken that concurrent prescription of drugs and exercise are not in conflict. A patient taking a non-selective $\beta$ blocker and a fibrate (a not uncommon combination) might have considerable difficulty in taking modest exercise such as a brisk walk for one to two hours. Further studies are needed to find therapeutic regimens that reduce patients' risk of suffering from the effects of coronary artery disease but also allow exercise which may have the same goals and, in addition, improve the quality of life.

MARTIN J KENDALL ANTHONY HEAD

\section{Clinical Investigation Unit,}

Department of Medicine,

Queen Elizabeth Hospital

Birmingham B15 2TH

1 Gloag D. Exercise, fitness, and health. $B M F$ 1992;305:377-8. (15 August.)

2 Dufaux B, Assman G, Hollman W. Plasma lipoproteins and physical activity. In I Sports Med 1982;3:123-36.

3 Olsson G, Wikstrand J, Warnold I, Manger Cats V, McBoyle D, Herlitz J, et al. Metoprolol-induced reduction in postinfarction mortality: pooled results from five double blind randomised trials. Eur Heart f 1992;13:28-32.

EDIToR,-Daphne Gloag believes that there is no dispute that exercise is beneficial.' Although over 800 deaths have occurred in accidents during sports and leisure exercise in the last five reported years $(1986-90)^{2}$ as well as other deaths during exercise from pre-existing disease, the benefits of exercise with regard to mortality are well established, at least from the public health point of view. From this vantage, discounting the future health gains derived from fitness to set against the present hazards may not be appropriate. ${ }^{3}$ Last Saturday, however, when I played cricket in a team without its regular wicket keeper, who was in hospital recovering from a heart attack that occurred during a game of squash, against a team missing a player who had died after being struck by lightning during a cricket match, the balance was not so clear.

Furthermore, taking morbidity into account leaves matters still less clear cut. In 1988 over half a million people aged 16 and over and 200000 children attended accident and emergency departments in the United Kingdom after sports accidents occurring outside the home (unpublished data from home accident surveillance system 1988 , Consumer Safety Unit of Department of Trade and Industry). In 1987 the general household survey included 184 adults who had had sports accidents that resulted in contact with a doctor. ${ }^{+}$These patients took 670 days off work as a result Translating these small numbers into national estimates yields an estimated 1.5 million injurie related to exercise needing contact with a docto and 5.5 million days lost from work. A report, commissioned by the Sports Council of England on a national survey of injuries and illnesses related to sports and exercise in 17500 adults, which should be published later this year, shows that even these numbers underestimate the problem. In addition, many non-trivial injuries occur which are treated by physiotherapists, dentists, complementary therapists, nurses, and others, and there is the possibility of chronic conditions developing later in life.

Thus as well as indisputably conferring health benefits, exercise indisputably incurs substantial health costs. As always, the trick is to weigh these carefully against each other to determine whether exercise is, in fact, beneficial.

JON NICHOLL

Medical Care Research Unit,

Department of Public Health Medicine,

Sheffield S10 2RX

1 Cloag D. Exercise, fitness, and health. BMF 1992;305:377-8. (15 August.)

2 Office of Population Censuses and Surveys. Fatal accidents occurring during sporting and leisure activities 1986-1990. London: HMSO, 1988-91. (DH4 88/3, 88/6, 89/4, 90/4, 91/4.) 3 Discounting health care: only a matter of timing [editorial] Lancet 1992;340:148-9.

4 Office of Population Censuses and Surveys. General household survey, 1987 data. London: HMSO, 1990.

\section{Validating the SF-36}

EDITOR, - We would like to draw attention to a number of errors and anomalies of interpretation in Brazier and colleagues' paper on validating the SF-36 health survey questionnaire.

Firstly, it is inappropriate to attempt to validate a health survey questionnaire (the SF-36) against a measure of perceived distress (the Nottingham health profile). In addition to measuring different concepts, the items in the two measures were generated by different methods. In the SF-36, the items represent professionals' assumptions about issues of relevance to health status. The items in the Nottingham health profile were derived directly from patients and other lay people, describing their perceptions of ill health. It has also been made clear in the major publication on the measure that the Nottingham health profile is not suitable for use in general population or general practice surveys. The instrument works best with selected groups, particularly chronically ill and elderly patients. ${ }^{2}$ Furthermore, presenting two similar measures together is likely to lead to response bias.

Secondly, the paper does not report one of the Nottingham health profile's sections at all: sleep. Since sleep problems are common in ill health this would appear to be an important omission from the SF-36, possibly resulting from the method by which items were generated.

Thirdly, the authors claim that the test-retest values obtained for the SF-36 indicate excellent reliability. This is in fact incorrect, as the values are lower than those generally accepted as indicating that a scale is reliable. ${ }^{3}$

Lastly, if a questionnaire cannot be shown to be reliable then there is little value in testing its validity. However, even in the authors' own terms the validity of the SF-36 was not shown. The socioeconomic class gradients are not as consistent as would be expected on several of the dimensions. Two of the subscales do not correspond to the presence of chronic physical problems, and the correlations between dimensions do not accord with logic (vitality and mental health correlated $0 \cdot 69$ ).

A close inspection of the data presented in the paper suggests that they do not support either the reliability or the validity of the SF-36 in the United Kingdom. It is noteworthy that nothing has been published on the SF-36 in its country of origin.

We welcome this attempt to find a much needed measure for assessing health in the general population. However, the choice of a measure, the techniques by which it is tested, and the interpretation of data require more careful attention.

SONJA M HUNT STEPHEN P MCKENNA

Care Outcomes Group,

Rheumatology and Rehabilitation Research Unit,

School of Medicine,

School of Medicine,

Leeds LS2 8NZ

1 Brazier JE, Harper $\mathrm{R}$, Jones NMB, O'Cathain A, Thomas $\mathrm{KJ}$, Usherwood T, et al. Validating the SF-36 health survey
questionnaire: new outcome measure for primary care. $B M F$ questionnaire: new outcome

2 Hunt SM, McEwen J, McKenna SP. Measuring health status. London: Croom Helm, 1986.

3 McDowell I, Newell C. Measuring health: a guide to rating scales and questionnaires. New York: Oxford University Press, 1987.

EDITOR, - It is vital that the validity and reliability of health status measures are thoroughly investigated. Test-retest reliability is particularly important because measurement error can make it more difficult to detect real differences between populations. Although Brazier and colleagues have carried out a large and well designed evaluation of their version of the SF-36 health survey questionnaire,' we found their analysis of test-retest reliability incomplete. This aspect of their paper is highlighted by the claim of a level of test-retest 